\title{
Safety and efficacy of endoscopist-directed balanced propofol sedation during endoscopic retrograde cholangiopancreatography
}

\author{
Alon Lapidus ${ }^{a}$, Ian M. Gralneka,b, Alain Suissac, Kamel Yassinc, lyad Khamaysia,c \\ Technion-Israel Institute of Technology, Haifa, Israel; Emek Medical Center, Afula, Israel; Rambam Health Care \\ Campus, Haifa, Israel
}

Abstract

Background Endoscopist-directed balanced propofol sedation (BPS) appears to be safe and
effective for routine endoscopy. However, there are limited data on its use in endoscopic retrograde
cholangiopancreatography (ERCP). We evaluated the safety and efficacy of endoscopist-directed
BPS for ERCP, and compared patient outcomes with anesthesiologist-administered moderate sedation.

Methods This was a retrospective cohort study, using prospectively collected endoscopy data from a tertiary care medical center where endoscopist-directed BPS during ERCP is routine practice. Adverse outcomes included need for bag-mask ventilation or intubation, aborted ERCP due to sedation, hospital admission post-ERCP (outpatients)/change in the level of care (inpatients), and death within $24 \mathrm{~h}$.

Results A total of 501 patients underwent ERCP with the use of endoscopist-directed BPS: Cohort 1 - 380 (76\%) inpatients, mean age 64.1, 46\% male, 24\% American Society of Anesthesiologists physical status (ASA) score I, 65\% ASA II, 11\% ASA III. Concurrently, 24 patients received anesthesiologist-administered moderate sedation: Cohort 2 - 19 (79\%) inpatients, mean age 65.0, $67 \%$ male, $12 \%$ ASA I, 25\% ASA II, 38\% ASA III, 25\% ASA IV. In Cohort 1, none of the adverse outcomes were observed. Propofol dose was inversely correlated with age $(\mathrm{r}=-0.42, \mathrm{P}<0.001)$, ASA score $(\mathrm{r}=-0.19, \mathrm{P}<0.001)$, and Mallampati score $(\mathrm{r}=-0.24, \mathrm{P}<0.001)$. One patient in Cohort 2 who received anesthesiologist-administered BPS required bag-mask ventilation and the ERCP was prematurely aborted because of the sedation. There were no deaths from any cause within $24 \mathrm{~h}$ of ERCP.

Conclusion Endoscopist-directed BPS appears safe, efficacious, and feasible for ASA I-III patients undergoing inpatient or ambulatory ERCP.

Keywords Propofol, endoscopic retrograde cholangiopancreatography, balanced propofol sedation, endoscopy, anesthesiology, moderate sedation

Ann Gastroenterol 2019; 32 (3): 1-9

${ }^{a}$ The Ruth and Bruce Rappaport Faculty of Medicine,

Technion - Israel Institute of Technology, Haifa (Alon Lapidus, Ian

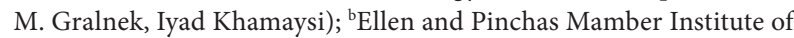
Gastroenterology, Hepatology, and Nutrition, Emek Medical Center, Afula (Ian M. Gralnek); 'Department of Gastroenterology, Rambam Health Care Campus, Haifa (Alain Suissa, Kamel Yassin, Iyad Khamaysi), Israel

Conflict of Interest: None

Correspondence to: Dr. Iyad Khamaysi, Advanced GI Endoscopy Unit, Department of Gastroenterology, Rambam Health Care Campus, Haifa, Israel. e-mail: iyad.khamaysi@gmail.com

Received 4 November 2018; accepted 17 January 2019; published online 15 February 2019

DOI: https://doi.org/10.20524/aog.2019.0360

\section{Introduction}

Fifty years ago, McCune et al published their landmark report on the "endoscopic cannulation of the ampulla of Vater", giving rise to endoscopic retrograde cholangiopancreatography (ERCP) [1]. Since then, there have been profound advancements in ERCP, including instrumentation and technology, clinical indications and procedural sedation.

Propofol (2,6-di-isoprpylphenol) is a safe and effective intravenously administered sedative agent with a rapid onset of action and fast recovery time [2,3]. Over the course of the past 3 decades, the use of propofol has evolved from use as a hypnotic agent, to use as an ultra-short acting sedative agent for induction and maintenance of anesthesia in monitored anesthesia 
care (MAC), to non-anesthesiologist-administered propofol (NAAP) in gastrointestinal (GI) endoscopic procedures [4,5].

In the framework of NAAP, balanced propofol sedation (BPS), defined as incremental doses of propofol in combination with fixed doses of an opioid (e.g., fentanyl) and a benzodiazepine (e.g., midazolam) [5], has gained acceptance as a useful and safe means of providing moderate sedation in GI endoscopic procedures [6-12]. This includes the use of BPS in advanced GI endoscopy procedures (e.g., ERCP) [13-17], where, compared to traditional moderate sedation, it has been found to be safe and beneficial in terms of shorter procedure and recovery times, high patient satisfaction, and similar rates of adverse events $[3,13,18]$.

However, the widespread use of BPS is hindered both by the agent's safety profile (risk of deep sedation leading to respiratory depression to the extent of apnea, with no known antagonists/ reversal agents) and by the US Food and Drug Administration (FDA) package labeling stating that propofol "should be administered only by persons trained in the administration of general anesthesia and not involved in the conduct of the surgical/diagnostic procedure" [19]. In an attempt to alter the package labeling of propofol, a petition was submitted to the FDA by the American College of Gastroenterology (ACG). That petition was denied by the FDA in 2010, on the grounds that the ACG failed to demonstrate an adequate safety profile of propofol to support their petition [20].

There are limited data regarding the safety profile of BPS under the direction of the endoscopist in ERCP procedures. Therefore, we aimed to evaluate the safety and efficacy of endoscopist-directed BPS, without MAC, during both inpatient and ambulatory ERCP procedures, performed in the advanced endoscopy procedure unit at a tertiary academic medical center. During the same study period, we also evaluated a control group of patients who underwent anesthesiologistadministered moderate sedation during ERCP procedures in the same advanced endoscopy procedure unit.

\section{Patients and methods}

This study was a retrospective cohort study based on prospectively collected data from the electronic medical record of endoscopic procedures in the Department of Gastroenterology at the Rambam Health Care Campus, Haifa, Israel. The study included all patients who underwent an ERCP procedure using endoscopist-directed BPS or anesthesiologistadministered moderate sedation. The study cohorts were constructed based on the administrator of the sedation: "Cohort 1 " included all patients who received endoscopist-directed moderate sedation using BPS and "Cohort 2" included all patients who received anesthesiologist-administered moderate sedation. The selection of patients receiving anesthesiologistadministered moderate sedation was based upon underlying patient comorbidities and the clinical judgment of the endoscopy team.

In this tertiary care medical center, the routine practice for providing moderate sedation during GI endoscopic procedures, including ERCP, is endoscopist-directed BPS (defined as incremental doses of propofol in combination with fixed doses of an opioid (e.g., fentanyl) and a benzodiazepine (e.g., midazolam). The administration/direction of BPS is only authorized for those endoscopists who have up-to-date basic life support (BLS) and advanced cardiac life support (ACLS) certifications, and continuously attend and satisfactorily complete a biennial 1-day didactic course on sedation sponsored by the Israel Gastroenterology Association (IGA). The advanced GI endoscopy procedures unit is equipped with all necessary cardiopulmonary resuscitation equipment and medications, and the unit's nursing staff are also required to have up-to-date BLS and ACLS certification and to successfully complete the same IGA sedation course. The endoscopy team (endoscopist and endoscopy nurse) are responsible for monitoring the patient's vital signs (e.g., oxygen saturation level, blood pressure, and heart rate), and the endoscopist is responsible for directing the provision and dosing of the BPS. Capnography is not routinely performed.

All moderate sedation administered by endoscopists was using BPS. Sedation administered by anesthesiologists was aimed at achieving a moderate level of sedation by administration of propofol. However, in view of the inherently more complex clinical settings and their competency in the field of anesthesia, the anesthesiologists were at liberty to administer additional pharmacological agents based on their clinical judgement and experience.

The American Society of Anesthesiologists physical status (ASA) and Mallampati scores are pre-sedation patient risk stratification variables. The ASA score is a globally accepted tool for assessing patients' pre-procedure (pre-sedation) comorbidity status. The ASA score serves a key role in clinical practice and is widely assumed to have greater reliability in distinction between high- and low-risk patients, reflected in its inclusion as a pre-procedure stratifying tool in society guidelines [21-24]. Patients are graded based on their concurrent medical status and history, on a scale of I-VI (from no comorbidities to functionally brain dead, respectively), with a descriptor " $e$ " that can be added in emergency settings [25].

The patients included in this study were assigned an ASA score as part of their pre-ERCP assessment by the endoscopists. In a small fraction of patients, these data were missing and were determined post hoc based on their medical record. When sedation was administered by an anesthesiologist, the ASA score was determined by the anesthesiologist. In addition to the ASA score, the Mallampati score - a grade of 1-4 related to the laryngopharyngeal anatomy and reflecting the difficulty of rescue intubation [26] - was introduced into standard reporting by the endoscopist prior to ERCP at our institution. However, this score was not consistently reported and cannot be reproduced post hoc.

We also collected patient demographic variables (age, sex, indication for ERCP, type of ERCP - ambulatory or inpatient procedure); intraprocedural vital signs (pre/post: oxygen saturation, blood pressure, heart rate); intraprocedural variables (BPS drug dosages, need for bag-mask ventilation and/or endotracheal intubation, ERCP procedure aborted because of sedation); and patient outcome variables 
(hospitalization and level of care post-ERCP procedure, mortality within $24 \mathrm{~h}$ ). Prior to initiating data collection, on March 10, 2016, we received local Institutional Review Board (Rambam Health Care Campus Helsinki Review) approval to review the endoscopy electronic data registry and report on the aforementioned de-identified patient information.

\section{Statistical analysis}

Descriptive statistics were calculated for all parameters. For continuous variables, this included mean, standard deviation (SD) and range values. For non-continuous variables, counts and percentages were reported. Comparison of categorical data was performed using Student's $t$-test. Correlation coefficients were determined using the Pearson correlation coefficient for continuous variables and the Spearman rank correlation coefficient for ordinal variables. An a priori determined $\mathrm{P}<0.05$ was considered statistically significant. All analyses were performed using Microsoft Excel 2013 (Microsoft Corp, Redmond, WA, USA) and SPSS Statistics 17.0 (SPSS Inc., Chicago, IL, USA).

\section{Results}

From October 1, 2015 until March 31, 2017, 525 patients (mean age 64.1 years, $47 \%$ male) underwent ERCP performed by any one of the 5 interventional endoscopists (all Israel licensed and board-certified gastroenterologists) who routinely perform ERCP at the Rambam Health Care Campus. Of these patients, 501 (96\%) received endoscopist-directed BPS (Cohort 1) and 24 (4\%) received anesthesiologist-administered moderate sedation (Cohort 2).

Table 1 shows patient demographics and pre-moderate sedation variables for both of the study cohorts. Patient ages were similar between Cohort 1 and Cohort 2, with mean age of 64.1 years and 65.0 years, respectively. However, there was a difference in male/female ratio with $67 \%$ of patients in Cohort 2 being male compared to $46 \%$ in Cohort 1 . The majority of the ERCP procedures in both cohorts were inpatient procedures, with "suspected choledocholithiasis" making up close to $50 \%$ of the indications for ERCP, followed by "stent removal/replacement" and "evaluation of malignancy". Patients in Cohort 2 had a more severe pre-sedation comorbidity assessment, with $62.5 \%$ of patients having ASA III-IV scores, compared to only $11 \%$ of the patients in Cohort 1 . Furthermore,

Table 1 Patient demographics and pre-sedation variables

\begin{tabular}{|c|c|c|}
\hline Variable & $\begin{array}{l}\text { Cohort 1: Endoscopist-directed BPS } \\
\qquad(\mathrm{n}=501)(96 \%)\end{array}$ & $\begin{array}{l}\text { Cohort 2: Anesthesiologist-administered } \\
\text { moderate sedation }(n=24)(4 \%)\end{array}$ \\
\hline Age $($ mean \pm SD) & $64.1 \pm 18.9$ & $65.0 \pm 25.2$ \\
\hline Male sex & $232(46 \%)$ & $16(67 \%)$ \\
\hline Inpatient procedure & $380(76 \%)$ & $19(79 \%)$ \\
\hline \multicolumn{3}{|l|}{ Indication for ERCP } \\
\hline Suspected choledocholithiasis & $231(46 \%)$ & $12(50 \%)$ \\
\hline Stent removal/ replacement & $68(13 \%)$ & $2(8.3 \%)$ \\
\hline Evaluation of known/suspected malignancy & $62(12 \%)$ & $2(8.3 \%)$ \\
\hline Jaundice & $48(10 \%)$ & $1(4.2 \%)$ \\
\hline Post-hepatobiliary intervention complications & $40(8 \%)$ & 0 \\
\hline Abdominal pain & $8(2 \%)$ & $1(4.2 \%)$ \\
\hline Other/unspecified & $44(9 \%)$ & $6(25 \%)$ \\
\hline \multicolumn{3}{|l|}{ ASA score } \\
\hline ASA I & $121(24 \%)$ & $3(12.5 \%)$ \\
\hline ASA II & $324(65 \%)$ & $6(25 \%)$ \\
\hline ASA III & $56(11 \%)$ & $9(37.5 \%)$ \\
\hline ASA IV & 0 & $6(25 \%)$ \\
\hline Mallampati score ${ }^{*}$ & {$[\mathrm{n}=300]$} & {$[\mathrm{n}=16]$} \\
\hline I & $92(30.7 \%)$ & $2(12.5 \%)$ \\
\hline II & $182(60.7 \%)$ & $12(75 \%)$ \\
\hline III & $26(8.7 \%)$ & $2(12.5 \%)$ \\
\hline IV & 0 & 0 \\
\hline
\end{tabular}

${ }^{\star}$ Not consistently documented in the electronic medical record, so there are missing data

BPS, balanced propofol sedation; SD, standard deviation; ERCP, endoscopic retrograde cholangiopancreatography; ASA, American Society of Anesthesiologists 
all 6 ASA IV patients and 14\% of ASA III patients (i.e., 27\% of all patients with ASA III-IV scores) were administered moderate sedation by an anesthesiologist. This trend was not found for the Mallampati score.

Table 2 shows BPS drug dosages per study cohort, and specifically the propofol dosage stratified according to inpatient/ambulatory procedure, sex, ASA and Mallampati scores. Both cohorts received similar dosages of the BPS medications. In Cohort 1, no association was found between mean propofol dose and inpatient/ambulatory procedure type or sex; however, the mean propofol dose was significantly lower (24 mg lower) during inpatient ERCP procedures compared to ambulatory ERCP procedures $(172 \pm 98 \mathrm{mg}$ vs. $196 \pm 116 \mathrm{mg}$, respectively; $\mathrm{P}=0.022$ ). The propofol dose also differed significantly among the stratifications by ASA and Mallampati scores, and was found to inversely correlate with these scores: ASA score (I: $200 \pm 105 \mathrm{mg}$; II: $176 \pm 103 \mathrm{mg}$; III: $137 \pm 88 \mathrm{mg} ; \mathrm{r}=-0.16, \mathrm{P}=0.012)$; and Mallampati score (I: $211 \pm 109 \mathrm{mg}$; II: $175 \pm 91 \mathrm{mg}$; III: $135 \pm 105 \mathrm{mg}$; $\mathrm{r}=-0.53$, $\mathrm{P}<0.01$ ). The propofol dose also was found to correlate

Table 2 BPS drug dosages

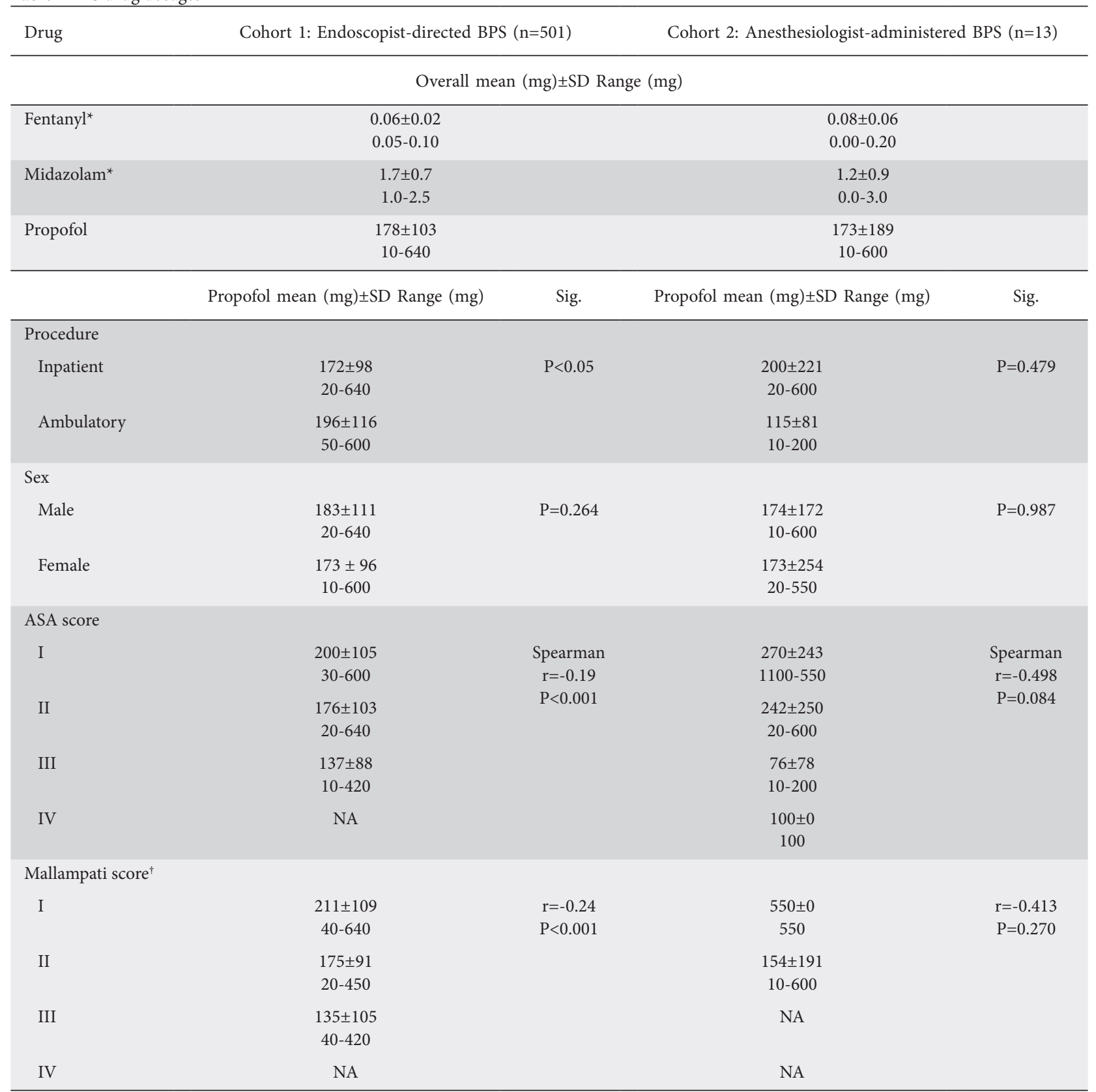

${ }^{\star}$ Data available for only 12 patients from Cohort 2

${ }^{\dagger}$ Not consistently documented in the electronic medical record, so there are missing data

BPS, balanced propofol sedation; SD, standard deviation; ASA, American Society of Anesthesiologists; Sig., significance; NA, not available 
inversely with patient age $(\mathrm{r}=-0.39, \mathrm{P}<0.01)$ : as patient age increased, the propofol dose decreased. Given the limited number of anesthesiologist-administered BPS ERCP procedures (Cohort 2), no statistically significant associations were observed. However, there was a trend towards inverse correlations, both between propofol dose and patient age $(\mathrm{r}=-0.52, \mathrm{P}=0.069)$, and between propofol dose and ASA score $(\mathrm{r}=-0.50, \mathrm{P}=0.084)$.

Table 3 shows the pre- and post-ERCP recorded vital signs. In both cohorts, no clinically significant differences were found between the pre-procedure and post-procedure vital signs. In Cohort 1 , no patient required bag-mask ventilation, endotracheal intubation or hospital admission/ change in level of in-hospital care following ERCP. One patient in Cohort 2, who received anesthesiologistadministered BPS, required bag-mask ventilation and the ERCP was prematurely aborted because of sedation effects. There was no mortality from any cause within $24 \mathrm{~h}$ of ERCP in either of the cohorts and all patients were discharged from the advanced endoscopy suite without any reported adverse events.

\section{Discussion}

Propofol, used alone or in combination with other medications to achieve moderate sedation in GI endoscopic procedures, reduces the times to induction and recovery, improves patient satisfaction with the endoscopic procedure, and has not been shown to be associated with an increased incidence of cardiopulmonary events [27-34]. Moreover, there is no evidence showing that anesthesiologist-administered propofol and MAC are superior to endoscopist-directed/ administered propofol in terms of endoscopic procedure efficacy or patient safety. On the contrary, because BPS uses smaller, incremental doses of propofol, it is thought to reduce the risk of inducing deep sedation with its attendant adverse effects, regardless of who delivers the sedation [5].

Despite propofol becoming a popular sedation agent for GI endoscopic procedures in many places in the world (e.g., North America, Europe and Israel), regulatory (FDA [19]) and societal guidelines (e.g., ASA [35], European Society of Anesthesiology (ESA) [36]) require propofol to be administered only by an anesthesiologist. This results in a considerable financial burden to the healthcare system for

Table 3 Patient vital signs

\begin{tabular}{cc}
\hline Signs & Cohort 1: Endoscopist-directed BPS ( $\mathrm{n}=501)$ \\
Mean \pm SD Range & Cohort 2: Anesthesiologist-administered sedation (n=24) \\
Mean \pm SD Range
\end{tabular}

\begin{tabular}{|c|c|c|}
\hline \multicolumn{3}{|c|}{$\mathrm{O}_{2}$ Saturation (\%) } \\
\hline $\mathrm{Pre}^{\mathrm{a}}$ & $\begin{array}{l}98 \pm 2.0 \\
90-100\end{array}$ & $\begin{array}{l}97 \pm 3.5 \\
88-100\end{array}$ \\
\hline Post $^{\mathrm{b}}$ & $\begin{array}{l}98 \pm 1.7 \\
90-100\end{array}$ & $\begin{array}{l}98 \pm 1.7 \\
94-100\end{array}$ \\
\hline \multicolumn{3}{|c|}{ Systolic BP (mmHg) } \\
\hline $\mathrm{Pre}^{\mathrm{c}}$ & $\begin{array}{l}143 \pm 26 \\
84-223\end{array}$ & $\begin{array}{l}129 \pm 25 \\
81-187\end{array}$ \\
\hline Post $^{\mathrm{b}}$ & $\begin{array}{c}139 \pm 28 \\
66-245\end{array}$ & $\begin{array}{c}129 \pm 28 \\
94-225\end{array}$ \\
\hline \multicolumn{3}{|c|}{ Diastolic BP (mmHg) } \\
\hline $\mathrm{Pre}^{\mathrm{c}}$ & $\begin{array}{c}82 \pm 14 \\
45-150\end{array}$ & $\begin{array}{c}74 \pm 14 \\
49-97\end{array}$ \\
\hline Post $^{\mathrm{b}}$ & $\begin{array}{c}81 \pm 15 \\
41-129\end{array}$ & $\begin{array}{c}76 \pm 18 \\
51-120\end{array}$ \\
\hline \multicolumn{3}{|c|}{ Heart rate (bpm) } \\
\hline $\mathrm{Pre}^{\mathrm{c}}$ & $\begin{array}{c}78 \pm 14 \\
43-142\end{array}$ & $\begin{array}{c}80 \pm 14 \\
57-108\end{array}$ \\
\hline Post $^{\mathrm{b}}$ & $\begin{array}{c}79 \pm 14 \\
45-143\end{array}$ & $\begin{array}{l}89 \pm 20 \\
68-135\end{array}$ \\
\hline
\end{tabular}

${ }^{\mathrm{a}}$ Missing data for 4 patients from Cohort 2

${ }^{\mathrm{b}}$ Missing data for 2 patients from Cohort 2

${ }^{\mathrm{c}}$ Missing data for 3 patients from Cohort 2

$B P S$, balanced propofol sedation; SD, standard deviation; BP, blood pressure; bpm, beats per min 
GI endoscopic procedures or the use of inferior moderate sedation medications [37]. Endoscopist-directed BPS can provide safe and effective moderate sedation, while saving the high associated costs of anesthesiologist services during GI endoscopy procedures. The additional cost of including an anesthesia specialist in GI endoscopic procedures is estimated to be one third of the procedure cost, or approximately $\$ 450$ per procedure (range \$150-1500), depending on the local economic environment $[5,38,39]$, resulting in an exceedingly high cost for each life-year saved of \$5.3 million [9].

Existing evidence and published guidelines regarding the safety and efficacy of NAAP [17] pertain mainly to the administration of propofol by a healthcare professional who has been specifically trained to administer the agent and who is not the active GI endoscopist performing the endoscopic procedure [6,38,40-44]. Although this would relieve the necessity for an anesthesiologist in the procedure, significant limitations remain, including associated personnel costs. It has been reported that having a dedicated healthcare professional administer and monitor propofol costs an estimated additional $\$ 403$ per patient. However, if it is administered by a registered nurse, who is part of the endoscopy team, the cost would be comparable to that of using traditional moderate sedation regimens [45]. In European countries, not bound by FDA regulations, NAAP is becoming more popular. In 2010, guidelines for NAAP training for GI endoscopy procedures were jointly published by the European Society of Gastrointestinal Endoscopy (ESGE), the European Society of Gastroenterology and Endoscopy Nurses Associates (ESGENA) and the ESA [18]. However, unfortunately, the ESA retracted its endorsement of the guideline in 2012, citing an inability to gain support for the guideline from individual European national anesthesiology societies $[36,46]$. The ESGE and ESGENA subsequently published updated sedation guidelines for GI endoscopy procedures in 2015 [21].

Despite the aforementioned activity in the area of propofol in GI endoscopy procedures, there is a paucity of data regarding the safety profile and the efficacy of endoscopist-directed propofol sedation $[27,28,32,45]$ and BPS [47] in ERCP procedures. Only 867 patients in 10 English-language studies have been reported on in meta-analyses $[16,17,33]$. Of these studies, the largest single study reported on 156 patients who received endoscopistdirected propofol sedation [40]. It is logical to assume that the key to relieving the financial burden of using propofol as part of a moderate sedation regimen is through demonstration of its safety and efficacy when given by the endoscopist $[14,15]$. In fact, this has already been shown to be the case in routine colonoscopy and esophagogastroduodenoscopy procedures, according to several reports [7-11]. Recently, we also reported on the safety and efficacy of endoscopist-directed BPS in over 1000 outpatient colonoscopies in low (ASA I and II) as well as higher-risk (ASA III) patients [12].

In this present study, we found that endoscopist-directed BPS appears to be safe and effective in achieving moderate sedation during ERCP, in both inpatient and outpatient settings, for patients with ASA and Mallampati scores of I-III. In our institution, sedation in ERCP is directed by the endoscopists; anesthesiologist-administered sedation is reserved for more complex clinical settings, resulting in inherent differences between the two study cohorts in terms of number of patients, patient demographics, clinical setting and mode of sedation. These differences notwithstanding, the safety of endoscopist-directed BPS was shown to be comparable to that of procedures performed during the same period in Cohort 2. As this study only evaluated the administration of BPS and not the use of propofol as a single sedation agent, the observed mean propofol dose/dosing range in both study cohorts was considerably lower (178 $\pm 103 / 10-640 \mathrm{mg}$ vs. $173 \pm 189 / 10$ $600 \mathrm{mg}$, for Cohort 1 vs. Cohort 2, respectively) than what has been reported for single-agent propofol in ERCP (388 $\pm 312 / 90$ $1100 \mathrm{mg}$ ) [27]. In Cohort 1, inverse correlations were found between the propofol dose and the patients' age, ASA and Mallampati scores, as has been reported elsewhere [11]. Thus, as patient age, comorbidities, and Mallampati scores increased, the dose of propofol administered decreased. Although statistically significant differences were found between the pre- and post-procedure vital signs in Cohort 1, these observed differences are unlikely to be of clinical significance. Furthermore, no patient was described as having hemodynamic instability during the ERCP procedures. BPS in ERCP appears to be safe, with no patient in Cohort 1 requiring bag-mask ventilation, endotracheal intubation or hospital admission (ambulatory procedure)/change in level of hospital care (inpatient procedure), following ERCP. In addition, there were no aborted ERCP procedures secondary to BPS sedation and no mortalities within $24 \mathrm{~h}$ of the procedure. All patients were discharged from the advanced endoscopy procedure unit without adverse events.

As reflected by the inherent differences between the two study cohorts reported in this study, the major distinction between them in the data collected was in the distribution of ASA scores within the cohorts. The ASA scoring tool has been shown to lack high interobserver reliability in grading and consistently reported differences have not been found between graders in relation to training, specialty, experience or age [48-50]. To our knowledge, there have been no studies specifically comparing the interobserver reliability of grading between endoscopist and anesthesiologist. As almost all endoscopy guidelines refer to the assessment of the ASA score as a pre-procedure risk stratification tool, further evaluation of the utility of the ASA score should be pursued.

In Cohort 2, 62.5\% of the patients were high-risk (ASA III-IV) compared to only $11 \%$ of the patients in Cohort 1. This finding is not surprising, since the patients in Cohort 2 received moderate sedation by an anesthesiologist based on the clinical setting and the patient's pre-procedure assessment, including among other things the ASA score. Patients in Cohort 2 had a higher risk, or a more complex clinical setting, or a combination of the two. From the entire study population, 454 patients were classified as ASA I-II and 65 as ASA III; of these $98 \%(n=445)$ and $84 \%(n=56)$, respectively, received endoscopist-directed BPS. Although only making up a small percentage of the overall study cohort, the subgroup of ASA III patients $(n=56)$ is important as it demonstrates the apparent 
safety of endoscopist-directed BPS for ERCP, even in this higher-risk patient population.

The recently updated ESGE guidelines "suggest primary involvement of an anesthesiologist" to administer propofol in patients with ASA and/or Mallampati scores $\geq 3$, or other medical conditions predisposing to a risk of airway obstruction. This, however, is classified as a "weak recommendation with low quality evidence", and is even less conclusive with respect to ERCP procedures [21]. Although not specifically addressed in the 2009 American Society for Gastrointestinal Endoscopy's (ASGE) position statement "NAAP for GI Endoscopy" [5], this was alluded to in the ASGE's 2008 guidelines for sedation and anesthesia in GI endoscopy, which stated that "assistance of an anesthesia specialist should be considered for ASA physical status III, IV and V patients" [51]. Likewise, it is the position of several national societies (e.g., Canada [22]) to recommend anesthesiologist support for ASA III or higher patients, while other societies deem NAAP appropriate in the setting of ASA I-III (e.g., Germany [23]).

It appears that our data, although not very comprehensive by general standards, do shed significant light on the specific context of the more challenging clinical setting of ERCP [15,52]. When combined with additional recent publications, they contribute to a growing evidence base of retrospective data showing the safety of endoscopic-directed BPS over the gamut of endoscopic procedures in low-, moderate- and high-risk patients (ASA I-III) [12]. As we have seen from the experience in our center, for an endoscopy team with the proper training and competency, this mode of patient stratification can avoid the additional cost of having an anesthesiologist present in more than $90 \%$ of ERCP procedures, with no effect on their safety and efficacy, thus allowing allocation of healthcare funds to the benefit of patients and healthcare systems in general.

This study had several limitations. The design was a retrospective cohort analysis, based on data prospectively collected over the course of 2 years in a single academic medical center's endoscopy unit. Thus, there were some missing data. The study cohorts were inherently different and were used to compare the incidence of the hard study endpoints defined a priori. Specifically, the Mallampati score was not collected consistently throughout the study timeframe. As the Mallampati score requires visual inspection of the patient, these data could not be collected post hoc; consequently, there were missing data (209 patients whose Mallampati score was not documented). This study was focused specifically on showing the safety and efficacy of endoscopist-directed BPS. Therefore, the only mode of propofol administration assessed was BPS and in no way should the results described herein be extrapolated to include any other form of propofol administration. In the study design, we also limited ourselves to evaluating hard endpoints, which in our opinion is appropriate for an initial demonstration of safety. In Israel, propofol administration is not reserved only for anesthesiologists alone, but is approved for physicians, among them endoscopists preforming BPS, who have up-to-date ACLS certification and have successfully completed sedation and airway management competency training. Thus, in no way should the data described herein be taken to imply that endoscopists in general can safely preform BPS, but only those adequately trained and certified [5,21-24,35]. Furthermore, future studies are required to fully elucidate the clinical decisions that result in the inclusion of anesthesiologists, because the decision is clearly not merely based on ASA and Mallampati score thresholds. The latter specifically, as it becomes a consistently reported pre-procedure variable in advanced endoscopy, needs to be further assessed in order to arrive at clearer thresholds for referral to an anesthesiologist. We also believe that there is room in future studies to include additional "softer" endpoints, such as transient oxygen desaturation, transient apnea, patient satisfaction, physician satisfaction, and more long-term adverse events (beyond $24 \mathrm{~h}$ ). Finally, our overall study sample was $n=501$, which represents approx. 50\% of the already published data on ERCP thus far. Nevertheless, this is a small sample size that may not be adequately statistically powered to definitively demonstrate the safety of endoscopist-directed BPS in ERCP. In light of the limitations described, there is a need for larger, prospective trials evaluating endoscopist-directed BPS in ERCP.

In conclusion, in both the inpatient and the ambulatory settings, we found endoscopist-directed BPS to be safe and effective in achieving moderate sedation in ERCP, in patients with ASA and Mallampati scores of I-III, having comparable safety and efficacy to ERCP procedures assisted by anesthesiologist-administered moderate sedation. We believe that endoscopist-directed BPS should be considered as the sedative method of choice during ERCP procedures. The administration of BPS by the endoscopist is only authorized to those endoscopists who have up-to-date BLS and ACLS certifications and who attend and satisfactorily complete a continuing didactic course on sedation.

\section{Summary Box}

\section{What is already known:}

- Endoscopist-directed balanced propofol sedation (BPS) is the routine practice at our institution for out- and inpatient endoscopic retrograde cholangiopancreatography (ERCP)

- Endoscopists maintain advanced cardiac life support certification and moderate sedation training

- Endoscopist-directed BPS has been shown to be safe and effective for American Society of Anesthesiologists physical status score I-III patients, to a degree comparable to ERCP procedures with anesthesiologist-administered sedation

\section{What the new findings are:}

- BPS was used not only in ambulatory cases, but also in the more challenging clinical setting of inpatients

- We performed 501 cases of ERCP with endoscopistdirected BPS without hard-endpoint adverse events 


\section{References}

1. McCune WS, Shorb PE, Moscovitz H. Endoscopic cannulation of the ampulla of Vater: a preliminary report. Gastrointest Endosc 1968;34:278-280.

2. Mackenzie N, Grant IS. Propofol for intravenous sedation. Anaesthesia 1987;42:3-6.

3. Shafer A, Doze VA, Shafer SL, White PF. Pharmacokinetics and pharmacodynamics of propofol infusions during general anesthesia. Anesthesiology 1988;69:348-356.

4. Smith I, White PF, Nathanson M, Gouldson R. Propofol. An update on its clinical use. Anesthesiology 1994;81:1005-1043.

5. Vargo JJ, Cohen LB, Rex DK, Kwo PY. Position statement: nonanesthesiologist administration of propofol for GI endoscopy. Gastrointest Endosc 2009;70:1053-1059.

6. Lee CK, Lee SH, Chung IK, et al. Balanced propofol sedation for therapeutic GI endoscopic procedures: a prospective, randomized study. Gastrointest Endosc 2011;73:206-214.

7. Lucendo AJ, Olveira A, Friginal-Ruiz AB, et al. Nonanesthesiologistadministered propofol sedation for colonoscopy is safe and effective: a prospective Spanish study over 1000 consecutive exams. Eur J Gastroenterol Hepatol 2012;24:787-792.

8. Sieg A, bng-Study-Group, Beck S, et al. Safety analysis of endoscopist-directed propofol sedation: a prospective, national multicenter study of 24441 patients in German outpatient practices. J Gastroenterol Hepatol 2014;29:517-523.

9. Rex DK, Deenadayalu VP, Eid E, et al. Endoscopist-directed administration of propofol: a worldwide safety experience. Gastroenterology 2009;137:1229-1237.

10. Rex DK, Overley C, Kinser K, et al. Safety of propofol administered by registered nurses with gastroenterologist supervision in 2000 endoscopic cases. Am J Gastroenterol 2002;97:1159-1163.

11. Cohen LB, Dubovsky AN, Aisenberg J, Miller KM. Propofol for endoscopic sedation: A protocol for safe and effective administration by the gastroenterologist. Gastrointest Endosc 2003;58:725-732.

12. Nathan JH, Klein A, Gralnek IM, Khamaysi I. Endoscopistdirected balanced propofol sedation is safe and effective in patients undergoing outpatient colonoscopy. J Dig Endosc 2015;6:158-162.

13. Coté GA, Hovis RM, Ansstas MA, et al. Incidence of sedationrelated complications with propofol use during advanced endoscopic procedures. Clin Gastroenterol Hepatol 2010;8:137-142.

14. Lee SH. Non-anesthesiologist administered propofol with or without midazolam for moderate sedation-the problem is not "which regimen" but "who's regimen". Dig Dis Sci 2012;57:2243-2245.

15. Burtea DE, Dimitriu A, Maloş AE, Săftoiu A. Current role of non-anesthesiologist administered propofol sedation in advanced interventional endoscopy. World J Gastrointest Endosc 2015;7:981-986.

16. Sethi S, Wadhwa V, Thaker A, et al. Propofol versus traditional sedative agents for advanced endoscopic procedures: a metaanalysis. Dig Endosc 2014;26:515-524.

17. Goudra BG, Singh PM, Gouda G, et al. Safety of non-anesthesia provider-administered propofol (NAAP) sedation in advanced gastrointestinal endoscopic procedures: comparative meta-analysis of pooled results. Dig Dis Sci 2015;60:2612-2627.

18. Dumonceau JM, Riphaus A, Aparicio JR, et al. NAAP Task Force Members. European Society of Gastrointestinal Endoscopy, European Society of Gastroenterology and Endoscopy Nurses and Associates, and the European Society of Anaesthesiology Guideline: Non-anesthesiologist administration of propofol for GI endoscopy. Endoscopy 2010;42:960-974.

19. FDA. Center for Drug Evaluation and Research: draft final printed labeling. http://www.accessdata.fda.gov/drugsatfda_docs/
anda/2000/75392_Propofol_Prntlbl.pdf [Accessed 4 February 2019].

20. American Society of Anesthesiologists. FDA upholds ASA stance on safe use of propofol. https://www.asahq.org/about-asa/ newsroom/news-releases/2010/08/fda-upholds-asa-stance-onsafe-use-of-propofol?page $=22$ [Accessed 4 February 2019].

21. Dumonceau JM, Riphaus A, Schreiber F, et al. Non-anesthesiologist administration of propofol for gastrointestinal endoscopy: European Society of Gastrointestinal Endoscopy, European Society of Gastroenterology and Endoscopy Nurses and Associates Guideline-Updated June 2015. Endoscopy 2015;47:1175-1189.

22. Byrne MF, Chiba N, Singh H, Sadowski DC; Clinical Affairs Committee of the Canadian Association of Gastroenterology. Propofol use for sedation during endoscopy in adults: a Canadian Association of Gastroenterology position statement. Can J Gastroenterol 2008;22:457-459.

23. Riphaus A, Wehrmann T, Weber B, et al. Gesellschaft für Recht und Politik im Gesundheitswesen (GPRG). [S3-guidelines-sedation in gastrointestinal endoscopy]. Z Gastroenterol 2008;46:1298-1330.

24. Vargo JJ, DeLegge MH, Feld AD, et al. Society for Gastroenterology Nurses and Associates. Multisociety sedation curriculum for gastrointestinal endoscopy. Gastrointest Endosc 2012;76:e1-e25.

25. Doyle DJ, Garmon EH. American Society of Anesthesiologists classification (ASA class). Treasure Island (FL): StatPearls Publishing; 2018.

26. Mallampati SR, Gatt SP, Gugino LD, et al. A clinical sign to predict difficult tracheal intubation: a prospective study. Can Anaesth Soc J 1985;32:429-434.

27. Wehrmann T, Kokabpick S, Lembcke B, Caspary WF, Seifert H. Efficacy and safety of intravenous propofol sedation during routine ERCP: a prospective, controlled study. Gastrointest Endosc 1999;49:677-683.

28. Riphaus A, Stergiou N, Wehrmann T. Sedation with propofol for routine ERCP in high-risk octogenarians: a randomized, controlled study. Am J Gastroenterol 2005;100:1957-1963.

29. Jung M, Hofmann C, Kiesslich R, Brackertz A. Improved sedation in diagnostic and therapeutic ERCP: propofol is an alternative to midazolam. Endoscopy 2000;32:233-238.

30. Chen WX, Lin HJ, Zhang WF, et al. Sedation and safety of propofol for therapeutic endoscopic retrograde cholangiopancreatography. Hepatobiliary Pancreat Dis Int 2005;4:437-440.

31. Krugliak P, Ziff B, Rusabrov Y, Rosenthal A, Fich A, Gurman GM. Propofol versus midazolam for conscious sedation guided by processed EEG during endoscopic retrograde cholangiopancreatography: a prospective, randomized, doubleblind study. Endoscopy 2000;32:677-682.

32. Kongkam P, Rerknimitr R, Punyathavorn S, et al. Propofol infusion versus intermittent meperidine and midazolam injection for conscious sedation in ERCP. J Gastrointestin Liver Dis 2008; 17:291-297.

33. Bo LL, Bai Y, Bian JJ, Wen PS, Li JB, Deng XM. Propofol vs traditional sedative agents for endoscopic retrograde cholangiopancreatography: a meta-analysis. World J Gastroenterol 2011; 17:3538-3543.

34. Deenadayalu VP, Eid EF, Goff JS, et al. Non-anesthesiologist administered propofol sedation for endoscopic procedures: a worldwide safety review. Gastrointest Endosc 2008;67:AB107. [Abstract].

35. American Society of Anesthesiologists; Committee on Ambulatory Surgical Care. Statement on safe use of propofol. https://www. asahq.org/standards-and-guidelines/statement-on-safe-use-ofpropofol [Accessed 2 February 2019].

36. Pelosi P. Retraction of endorsement: European Society of Gastrointestinal Endoscopy, European Society of Gastroenterology and Endoscopy Nurses and Associates, and the European Society of 
Anaesthesiology Guideline: Non-anesthesiologist administration of propofol for GI endoscopy. Endoscopy 2012;44:302; author reply 302 .

37. Aisenberg J, Brill JV, Ladabaum U, Cohen LB. Sedation for gastrointestinal endoscopy: new practices, new economics. Am J Gastroenterol 2005;100:996-1000.

38. Hassan C, Rex DK, Cooper GS, Benamouzig R. Endoscopistdirected propofol administration versus anesthesiologist assistance for colorectal cancer screening: a cost-effectiveness analysis. Endoscopy 2012;44:456-464.

39. Brill JV. Endoscopic sedation: legislative update and implications for reimbursement. Gastrointest Endosc Clin N Am 2008;18:665678, viii.

40. Khan HA, Umar M, Tul-Bushra H, Nisar G, Bilal M, Umar S. Safety of non-anaesthesiologist-administered propofol sedation in ERCP. Arab J Gastroenterol 2014;15:32-35.

41. Wehrmann T, Triantafyllou K. Propofol sedation in gastrointestinal endoscopy: a gastroenterologist's perspective. Digestion 2010;82:106-109.

42. Angsuwatcharakon P, Rerknimitr R, Ridtitid W, et al. Cocktail sedation containing propofol versus conventional sedation for ERCP: a prospective, randomized controlled study. $B M C$ Anesthesiol 2012;12:20.

43. Lee TH, Lee CK, Park SH, et al. Balanced propofol sedation versus propofol monosedation in therapeutic pancreaticobiliary endoscopic procedures. Dig Dis Sci 2012;57:2113-2121.

44. Schilling D, Rosenbaum A, Schweizer S, Richter H, Rumstadt B. Sedation with propofol for interventional endoscopy by trained nurses in high-risk octogenarians: a prospective, randomized, controlled study. Endoscopy 2009;41:295-298.
45. Vargo JJ, Zuccaro G Jr, Dumot JA, et al. Gastroenterologistadministered propofol versus meperidine and midazolam for advanced upper endoscopy: a prospective, randomized trial. Gastroenterology 2002;123:8-16.

46. Perel A. Non-anaesthesiologists should not be allowed to administer propofol for procedural sedation: a Consensus Statement of 21 European National Societies of Anaesthesia. Eur J Anaesthesiol 2011;28:580-584.

47. Ikeuchi N, Itoi T, Gotoda T, et al. Feasibility of non-anesthesiologistadministered propofol sedation for emergency endoscopic retrograde cholangiopancreatography. Gastroenterol Res Pract 2015;2015:685476

48. Aronson WL, McAuliffe MS, Miller K. Variability in the American Society of Anesthesiologists Physical Status Classification Scale. AANA J 2003;71:265-274.

49. De Cassai A, Boscolo A, Tonetti T, Ban I, Ori C. The assignment of ASA-physical status relates to anesthesiologist's experience: a survey-based national-study. Korean J Anesthesiol 2018 Nov 14 [Epub ahead of print].

50. Sankar A, Johnson SR, Beattie WS, Tait G, Wijeysundera DN Reliability of the American Society of Anesthesiologists physical status scale in clinical practice. Br J Anaesth 2014;113:424-432.

51. Lichtenstein DR, Jagannath S, Baron TH, et al. Standards of Practice Committee of the American Society for Gastrointestinal Endoscopy. Sedation and anesthesia in GI endoscopy. Gastrointest Endosc 2008;68:815-826.

52. Cheriyan DG, Byrne MF. Propofol use in endoscopic retrograde cholangiopancreatography and endoscopic ultrasound. World $J$ Gastroenterol 2014;20:5171-5176. 